\title{
Factors related to lithium blood concentrations in Chinese Han patients with bipolar disorder
}

This article was published in the following Dove Press journal:

Neuropsychiatric Disease and Treatment

\author{
Ya-Yun $X u^{1,2, *}$ \\ Qian-Hui $X_{i a}{ }^{3} *$ \\ Jun Liang ${ }^{1,2}$ \\ Yin Cao ${ }^{1,2}$ \\ Feng Shan ${ }^{1,2}$ \\ Yang Liu ${ }^{1,2}$ \\ Chun-Yu Yan ${ }^{1,2}$ \\ Qing-Rong $\mathrm{Xia}^{1,2}$
}

'Department of Pharmacy, Hefei Fourth People's Hospital, Hefei 230000, People's Republic of China; ${ }^{2}$ Psychopharmacology Research Laboratory, Anhui Mental Health Center, Hefei 230000, People's Republic of China; ${ }^{3}$ School of Pharmacy, Wannan Medical College, Wuhu 241002, People's Republic of China

*These authors contributed equally to this work
Correspondence: Qing-Rong Xia Department of Pharmacy, Hefei Fourth People's Hospital, Anhui Mental Health Center, 316 Huangshan Road, Hefei 230000, People's Republic of China $\mathrm{Tel} / \mathrm{Fax}+8655163616022$

Email ahmcxqr@I63.com
Background: The goal of this study was to identify the physiological factors related to the blood concentration of lithium in Chinese Han patients with bipolar disorder (BD).

Materials and methods: A total of 186 Chinese Han patients with BD were assessed. Patients were recruited from the Anhui Mental Health Center. The concentrations of serum lithium were measured by a Dimension RxL Max biochemistry analyzer. Physiological factors, including body weight, body mass index (BMI), and routine laboratory parameters, were collected. Relationships between the serum lithium concentration and relevant clinical data were analyzed by Pearson correlation tests, and the independent relationships were determined by multivariate linear regression analysis.

Results: Pearson correlation analysis showed that serum lithium concentrations were positively correlated with creatinine concentrations $(\mathrm{r}=0.147, P=0.046), \mathrm{Mg}^{2+}$ concentrations $(\mathrm{r}=0.151, P=0.04)$, and the percentage of neutrophils $(\mathrm{r}=0.178, P=0.015)$ and negatively correlated with high-density lipoprotein (HDL) concentrations $(\mathrm{r}=-0.142, P=0.05)$, apolipoprotein $\mathrm{A} 1$ concentrations $(\mathrm{r}=-0.169, P=0.02)$, and $\mathrm{Na}^{+}$concentrations $(\mathrm{r}=-0.148, P=0.046)$ in 186 patients with BD. Furthermore, multivariate linear regression analysis showed that serum lithium concentrations were negatively associated with $\mathrm{Na}^{+}$concentrations and positively associated with the percentage of neutrophils.

Conclusion: These results suggest that physiological factors, including creatinine, HDL, apolipoprotein $\mathrm{A} 1, \mathrm{Na}^{+}$, and $\mathrm{Mg}^{2+}$ concentrations and percentage of neutrophils, might be related to serum lithium concentrations and provide a basis for parameter selection of lithium population pharmacokinetics in Chinese Han patients with BD.

Keywords: bipolar disorder, apolipoprotein A1, creatinine, high-density lipoprotein, neutrophil, lithium

\section{Introduction}

Bipolar disorder (BD), a chronic, severe, and highly disabling psychiatric illness, is among the leading causes of disability, giving rise to tremendous health-care costs and affecting more than $1 \%$ of the general population irrespective of nationality, ethnic origin, or socioeconomic status. ${ }^{1}$ Lithium is still a first-line treatment for $\mathrm{BD},{ }^{2}$ even though individual response is variable. Given that lithium has a narrow therapeutic index, therapeutic drug monitoring for determining serum lithium concentrations and exploring factors related to lithium blood concentrations remain the key components of clinical surveillance. ${ }^{3}$

Over the past two decades, China has experienced rapid socio-economic changes, accompanied by social problems, such as the rapid rise in health care costs, the rise in divorce rates, the weakening of family relations, the massive 
migration of temporary jobs to urban areas and the widening poverty gap. ${ }^{4}$ These problems generally affect mental health, especially emotional disorders including BD. It has been reported that the 12-month and lifetime prevalence of Chinese BD were $0.17 \%$ and $0.11 \%$, respectively. ${ }^{5}$ Chinese populations make up around one fifth of the total world and the Han nationality accounts for $92 \%$ of the total population. Taken together the fact that lithium is a first-line treatment for BD in China and the study on relative factors of blood lithium has not been widely reported in Chinese Han population, it was important and necessary to investigate the factors related to lithium blood concentrations in Chinese Han patients with BD.

The current study has suggested that body size, age and renal function are associated with lithium clearance. ${ }^{6}$ Further study showed that lower lithium clearance could be attributed to the loss of fluid and sodiumions $\left(\mathrm{Na}^{+}\right){ }^{7}$ Additionally, most drug interactions with lithium are associated with changes in fluid or $\mathrm{Na}^{+}$balance. ${ }^{8}$ However, the factors relating the concentration of blood lithium are still incompletely understood and remain controversial, especially in Chinese Han patients with BD.

Pharmacokinetic studies showed that lithium is mainly excreted by glomerular filtration, ${ }^{9}$ and it is speculated that the significant predictors of lithium clearance identified in most studies were related to renal function, such as glomerular filtration rate (GFR). ${ }^{6,10}$ However, there are few studies on the relationship between blood lithium concentration and renal function. Therefore, correlations between endogenous markers of GFR (urea nitrogen and creatinine) and serum lithium concentration were observed in the present study.

There is growing evidence that lipid alterations play an important role in the pathophysiology of $\mathrm{BD} .{ }^{11}$ As a valuable first-line treatment for $\mathrm{BD}$, lithium was considered to affect lipid alterations. In agreement with this notion, it has been reported that the serum levels of apolipoprotein A1, a major component of the high-density lipoprotein (HDL) complex, were decreased in patients with BD but can be restored to control levels under lithium treatment. ${ }^{12}$ Moreover, animal experiments showed that serum enzyme levels of HDL were reduced significantly in lithium-treated rats, depicting the disturbed general physiological status. ${ }^{13}$ These findings suggest that concentrations of serum lithium may be related to lipid metabolism.

Recent studies have shown a link between blood lithium and electrolyte imbalance. The results of a case report demonstrated that blood lithium concentrations may be increased by a high-sodium diet. ${ }^{14}$ Nephrogenic diabetes insipidus, the most common adverse effect of lithium, occurs in up to $40 \%$ of patients receiving lithium treatment. ${ }^{15}$ Renal lithium toxicity, characterized by increased water and sodium diuresis, can result in insufficient blood volume, hypernatremia, hyperchloremic metabolic acidosis and distal tubular acidosis. ${ }^{15}$ Thus, whether the concentration of electrolytes in the blood could relate the lithium concentration was investigated in the present study.

Lithium carbonate was successfully used to treat drug (including paliperidone ${ }^{16}$ and clozapine ${ }^{17}$ )-induced leukopenia and neutropenia, indicating a correlation between lithium and changes in the hemogram. Therefore, the association between the concentration of lithium and the hemogram was also investigated.

Considering the potential relationships between blood lithium and renal function, lipid alterations, electrolyte imbalance, and hemogram changes, the current retrospective study sought to identify whether the above physiological factors could influence the serum lithium concentration in Chinese Han patients with BD.

\section{Materials and methods}

\section{Subjects}

This study was conducted at Hefei Fourth People's Hospital, Anhui Mental Health Center, between May 2018 and January 2019. Psychiatric diagnosis was established through an International Classification of Diseases 10th Revision (ICD-10) criteria-based structured clinical interview by skilled clinicians. A total of 610 subjects with BD were screened by an experienced researcher, and 186 patients were selected from the above patients. The criteria for joining the group were as follows: (1) age 18-65 years; (2) no use of antipsychotic, antimanic, antidepressant or antianxiety drugs for at least two weeks before admission or not undergone a washout period of at least five halflives of the above drugs; (3) no serious physical diseases, such as acute or chronic nephritis, cardiovascular disease, acute infection, or central nervous system diseases; and (4) written informed consent to participate in the study. Evidence of clinically significant medical problems through medical history, laboratory workup, and physical examination that evaluated for serious physical diseases, such as acute or chronic nephritis, cardiovascular disease, acute infection, or central nervous system diseases was exclusionary for participation. Figure 1 summarizes the recruitment process. In accordance with the principles of 


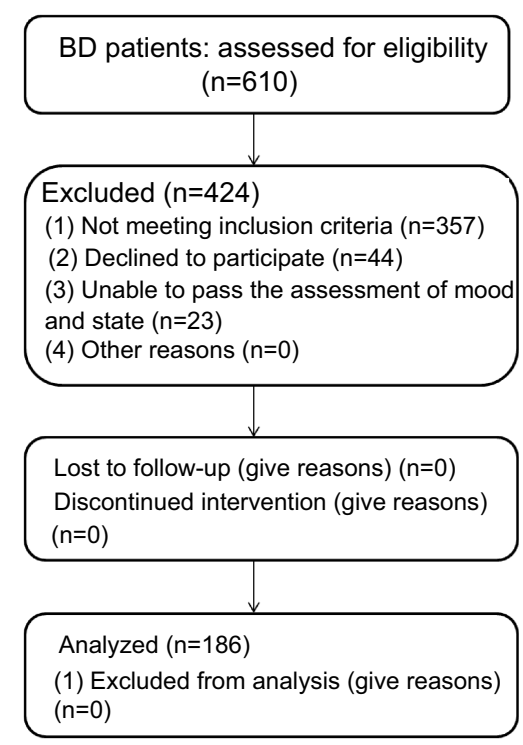

Figure I Flowchart of the recruitment of participants. Abbreviation: BD, bipolar disorder.

the Declaration of Helsinki, all subjects provided informed written consent prior to participation. The Ethics Committee of Hefei Fourth People's Hospital, Anhui Mental Health Center, approved this study.

\section{Collection of relevant clinical data}

A demographics questionnaire was used to collect general information about participants, such as sex, body weight, body mass index (BMI), and routine laboratory parameters, including biochemical indexes and clinical parameters. The biochemical indexes and clinical parameters were measured by a COBAS 8000 modular analyzer (Roche Diagnostics) and a Siemens ADVIA 2120i hematology analyzer (Siemens Healthcare Diagnostics Inc., Dublin, Ireland), respectively.

The biochemistry indexes were as follows: total bilirubin (TBIL), direct bilirubin (DBIL), total protein (TP), albumin,globulin, alanine aminotransferase (ALT), aspartate aminotransferase (AST), alkaline phosphatase (ALP), $\gamma$-glutamyl transpeptidase $(\gamma$-GT), total bile acid (TBA), total cholesterol (TC), HDL, triglyceride (TG), apolipoprotein $\mathrm{A} 1$, apolipoprotein $\mathrm{B}$, blood urea nitrogen (BUN), creatinine (CRE), uric acid, $\mathrm{K}^{+}, \mathrm{Na}^{+}, \mathrm{Cl}^{-}, \mathrm{Ca}^{2+}$, creatine kinase (CK), glucose, and $\mathrm{Mg}^{2+}$.

The clinical parameters were as follows: white blood cell (WBC) count, neutrophil percentage, lymphocyte percentage, monocyte percentage, basophilic percentage, eosinophil percentage, number of neutrophils, number of lymphocytes, number of monocytes, number of eosinophils, number of basophils, number of red blood cells (RBCs), hemoglobin (HB) concentration, packed cell volume (PCV), mean corpuscular volume (MCV), mean corpuscular hemoglobin $(\mathrm{MCH})$, mean corpuscular hemoglobin concentration (MCHC), red cell distribution width coefficient of variation (RDW-CV), number of platelets, mean platelet volume (MPV), platelet distribution width (PDW), and platelet crit (PCT).

\section{Detection of blood lithium concentration}

The elimination half-life of lithium averages approximately 20-24 hrs, and steady-state concentrationsare reached after 5-7 days. ${ }^{6,18}$ Therefore, the steady-state blood lithium concentration was measured after administration of oral lithium carbonate $1.0 \mathrm{~g} / \mathrm{d}$ for 1 week. Blood samples were taken from the participants' veins at 5:00 a.m. All subjects were fasted prior to blood collection. Dry tubes without any additives were used for collecting the samples. The blood samples were immediately centrifuged at 3,000 rpm for 5 min at $4{ }^{\circ} \mathrm{C}$. The extracted supernatant was collected as a serum sample. The concentration of lithium in the serum was measured using a biochemical analyzer (Dimension RxL Max, SIEMENS Company, Germany) according to the manufacturer's instructions. Reagents (Lithium Flex reagent cartridge, lot: BA9101) were supplied by SIEMENS Company.

\section{Statistical analysis}

Data were analyzed using SPSS version 17.0 statistical analysis software (SPSS, Chicago, IL). Distribution of the data was determined by the Kolmogorov-Smirnov test. Relationships between the serum lithium concentration and relevant clinical data were analyzed using Pearson correlation tests, and multiple linear regression analysis was utilized to identify the factors including the creatinine, HDL, apolipoprotein $\mathrm{A} 1, \mathrm{Na}^{+}, \mathrm{Mg}^{2+}$ concentrations, and percentage of neutrophils related to the serum lithium concentrations. Quantitative data are reported as the means \pm standard deviation (SD). A $P$-value of $<0.05$ was considered indicative of statistical significance.

\section{Results}

One hundred and eighty-six Chinese Han patients with BD were enrolled. The demographic characteristics and routine laboratory parameters of all the subjects are shown in Table 1. 
Table I Distribution of independent variables measured from 186 patients with BD

\begin{tabular}{|c|c|c|c|c|}
\hline & Minimum & Maximum & Mean & Standard Deviation \\
\hline Age (year) & 20 & 65 & 35.15 & 10.92 \\
\hline BMI $\left(\mathrm{kg} / \mathrm{m}^{2}\right)$ & 19.14 & 37.87 & 24.21 & 4.41 \\
\hline Lithium concentration $(\mathrm{mmol} / \mathrm{L})$ & 0.11 & 1.34 & 0.60 & 0.23 \\
\hline TBIL (umol/L) & 1.90 & 29.50 & 7.71 & 4.38 \\
\hline DBIL (umol/L) & 1.50 & 17.90 & 3.33 & 1.77 \\
\hline $\operatorname{TP}(g / L)$ & 56.00 & 81.20 & 66.25 & 4.62 \\
\hline Albumin $(g / L)$ & 27.00 & 53.10 & 42.26 & 3.82 \\
\hline Globulin (g/L) & 16.20 & 43.00 & 23.88 & 3.40 \\
\hline ALT $(\mathrm{U} / \mathrm{L})$ & 5.00 & 168.00 & 25.84 & 22.82 \\
\hline AST (U/L) & 9.00 & 97.00 & 21.83 & 12.01 \\
\hline $\operatorname{ALP}(U / L)$ & 25.00 & 159.00 & 65.06 & 18.90 \\
\hline$\gamma$-GT (U/L) & 2.00 & 250.00 & 24.44 & 26.30 \\
\hline TBA (umol/L) & 0.30 & 34.10 & 5.10 & 4.97 \\
\hline $\mathrm{TC}(\mathrm{mmol} / \mathrm{L})$ & 1.08 & 7.89 & 4.06 & 0.91 \\
\hline $\mathrm{HDL}(\mathrm{mmol} / \mathrm{L})$ & 0.63 & 2.30 & 1.13 & 0.27 \\
\hline TG $(\mathrm{mmol} / \mathrm{L})$ & 0.42 & 7.80 & 1.80 & 1.25 \\
\hline Apolipoprotein AI (g/L) & 0.58 & 1.58 & 1.00 & 0.18 \\
\hline Apolipoprotein B $(g / L)$ & 0.39 & 1.40 & 0.75 & 0.19 \\
\hline $\mathrm{BUN}(\mathrm{mmol} / \mathrm{L})$ & 1.66 & 6.65 & 3.39 & 0.96 \\
\hline CRE (umol/L) & 35.00 & 107.00 & 64.45 & 12.92 \\
\hline Uric acid (umol/L) & 124.00 & 620.00 & 387.22 & 104.79 \\
\hline $\mathrm{K}^{+}(\mathrm{mmol} / \mathrm{L})$ & 3.44 & 437.00 & 6.65 & 31.73 \\
\hline $\mathrm{Na}^{+}(\mathrm{mmol} / \mathrm{L})$ & 134.40 & 145.20 & 139.82 & 1.81 \\
\hline $\mathrm{Cl}^{-}(\mathrm{mmol} / \mathrm{L})$ & 98.10 & 110.00 & 103.65 & 2.60 \\
\hline $\mathrm{Ca}^{2+}(\mathrm{mmol} / \mathrm{L})$ & 2.05 & 2.66 & 2.29 & 0.097 \\
\hline CK (U/L) & 22.00 & 567.00 & 77.19 & 66.86 \\
\hline Glucose $(\mathrm{mmol} / \mathrm{L})$ & 3.43 & 11.96 & 4.96 & 1.03 \\
\hline $\mathrm{Mg}^{2+}(\mathrm{mmol} / \mathrm{L})$ & 0.62 & 1.06 & 0.87 & 0.070 \\
\hline WBC $\left(10^{9} / \mathrm{L}\right)$ & 1.95 & $\mid 7.31$ & 7.54 & 2.35 \\
\hline Neutrophil percentage (\%) & 28.30 & 82.50 & 60.78 & 8.91 \\
\hline Lymphocyte percentage (\%) & 8.10 & 57.00 & 27.78 & 7.95 \\
\hline Monocyte percentage (\%) & 3.10 & 12.20 & 6.12 & 1.56 \\
\hline Basophilic percentage (\%) & 0.10 & 1.10 & 0.36 & 0.18 \\
\hline Eosinophil percentage (\%) & 0.10 & 12.90 & 3.24 & 2.14 \\
\hline Number of neutrophils $\left(10^{9} / \mathrm{L}\right)$ & 0.62 & 11.73 & 4.68 & 1.92 \\
\hline Number of lymphocytes $\left(10^{9} / \mathrm{L}\right)$ & 0.63 & 4.00 & 2.01 & 0.66 \\
\hline Number of monocytes $\left(10^{9} / \mathrm{L}\right)$ & 0.11 & 0.97 & 0.45 & 0.16 \\
\hline Number of eosinophils $\left(10^{9} / \mathrm{L}\right)$ & 0.00 & 0.93 & 0.24 & 0.16 \\
\hline Number of basophils $\left(10^{9} / \mathrm{L}\right)$ & 0.00 & 0.09 & 0.027 & 0.015 \\
\hline Number of RBC $\left(10^{12} / L\right)$ & 2.60 & 5.72 & 4.21 & 0.51 \\
\hline HB concentration $(g / L)$ & 94.00 & 162.00 & 129.14 & 14.44 \\
\hline PCV (\%) & 25.80 & 48.30 & 37.92 & 4.04 \\
\hline $\mathrm{MCV}(\mathrm{fl})$ & 68.90 & 101.70 & 90.13 & 4.05 \\
\hline $\mathrm{MCH}(\mathrm{pg})$ & 19.80 & 229.60 & 31.80 & 14.74 \\
\hline $\mathrm{MCHC}(\mathrm{g} / \mathrm{L})$ & 256.00 & 385.00 & 340.89 & 18.03 \\
\hline RDW-CV (\%) & 10.60 & 111.00 & 12.77 & 7.29 \\
\hline Number of platelets $\left(10^{9} / \mathrm{L}\right)$ & 58.00 & 413.00 & 207.66 & 56.60 \\
\hline MPV (fl) & 8.90 & 14.20 & 10.72 & 0.92 \\
\hline PDW (\%) & 31.40 & 64.80 & 42.38 & 6.21 \\
\hline РCT (\%) & 0.07 & 0.41 & 0.22 & 0.056 \\
\hline
\end{tabular}

Abbreviations: BD, bipolar disorder; BMI, body-mass-index; TBIL, total bilirubin; DBIL, direct bilirubin; TP, total Protein; ALT, alanine aminotransferase; AST, aspartate aminotransferase; ALP, alkaline phosphatase; $\gamma$-GT, $\gamma$-glutamyl transpeptidase; TBA, total bile acid; TC, total cholesterol; HDL, high-density lipoprotein; TG, triglyceride; BUN, blood urea nitrogen; CRE, creatinine; CK, creatine kinase; WBC, white blood cell; HB, hemoglobin; PCV, packed cell volume; MCV, mean corpuscular volume; $\mathrm{MCH}$, mean corpuscular hemoglobin; MCHC, mean corpuscular hemoglobin concentration; RDW-CV, red cell distribution width coefficient of variation; MPV, mean platelet volume; PDW, platelet distribution width; PCT, platelet crit. 


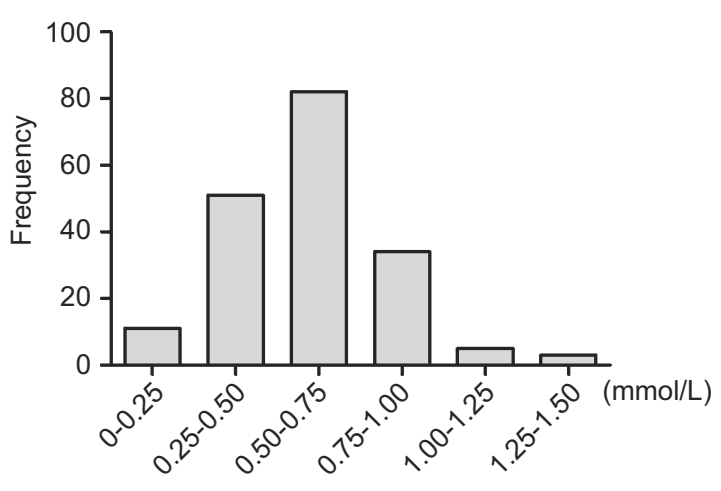

Figure 2 Histogram of resulting lithium concentration in 186 patients with bipolar disorder.

Figure 2 shows the distribution of the serum lithium concentration in patients with $\mathrm{BD}$. These data ranged from 0.11 to 1.34 (mean $=0.60, \mathrm{SD}=0.23) \mathrm{mmol} / \mathrm{L}$.

As shown in Figure 3, the results of the Pearson correlation analysis showed that serum lithium concentrations were positively correlated with creatinine concentrations $(\mathrm{r}=0.147$, $P=0.046$; Figure $3 \mathrm{~A}), \mathrm{Mg}^{2+}$ concentrations $(\mathrm{r}=0.151$, $P=0.04$; Figure $3 \mathrm{~B}$ ), and the percentage of neutrophils $(\mathrm{r}=0.178, P=0.015$; Figure $3 \mathrm{C})$ in 186 patients with BD.
As shown in Figure 4, the results of the Pearson correlation analysis showed that serum lithium concentrations were negatively correlated with $\mathrm{HDL}$ concentrations $(\mathrm{r}=-0.142, P=0.05$; Figure 4A), apolipoprotein A1 concentrations $(\mathrm{r}=-0.169$, $P=0.02$; Figure 4B), and $\mathrm{Na}^{+}$concentrations $(\mathrm{r}=-0.148$, $P=0.046$; Figure 4C) in 186 patients with BD.

Multivariate linear regression analysis showed that serum lithium concentrations were positively associated with the percentage of neutrophils and negatively associated with $\mathrm{Na}^{+}$concentration (Table 2).

\section{Discussion}

In the present study, we demonstrated that serum lithium concentrations were positively correlated with creatinine concentrations, $\mathrm{Mg}^{2+}$ concentrations, and the percentage of neutrophils and negatively correlated with HDL concentrations, apolipoprotein A1 concentrations, and $\mathrm{Na}^{+}$ concentrations by Pearson's correlation test. Multivariate linear regression analysis indicated that serum lithium concentrations were positively associated with the percentage of neutrophils and negatively associated with $\mathrm{Na}^{+}$ concentrations in Chinese Han patients with BD.
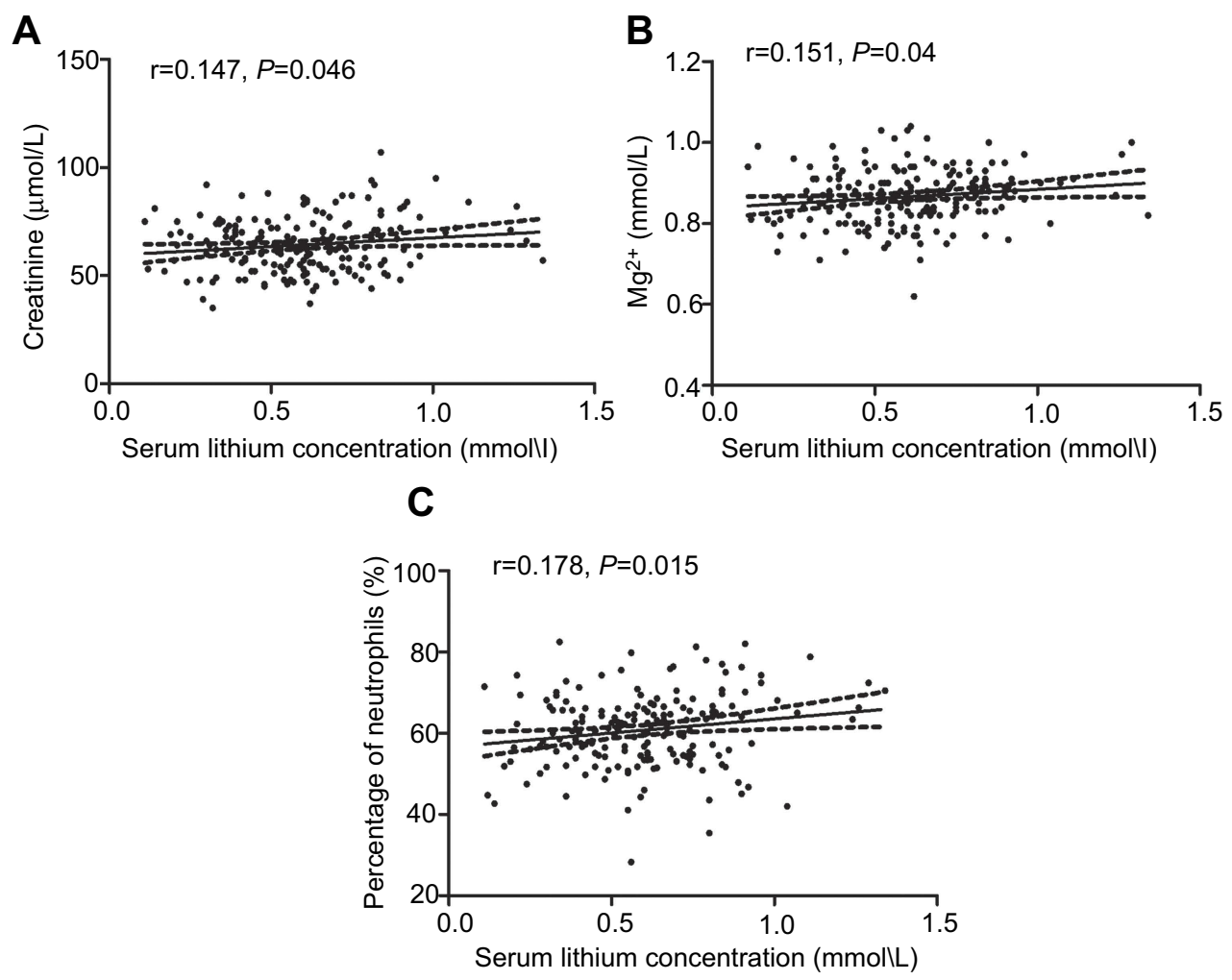

Figure 3 Positive correlations between serum lithium concentration and creatinine $(\mathbf{A}), \mathrm{Mg}^{2+}(\mathbf{B})$ concentrations, and percentage of neutrophils $(\mathbf{C})$ in 186 patients with bipolar disorder.

Notes: These data are normally distributed (Kolmogorov-Smirnov test). $P<0.05$ (two-tailed) was considered statistically significant. 
A

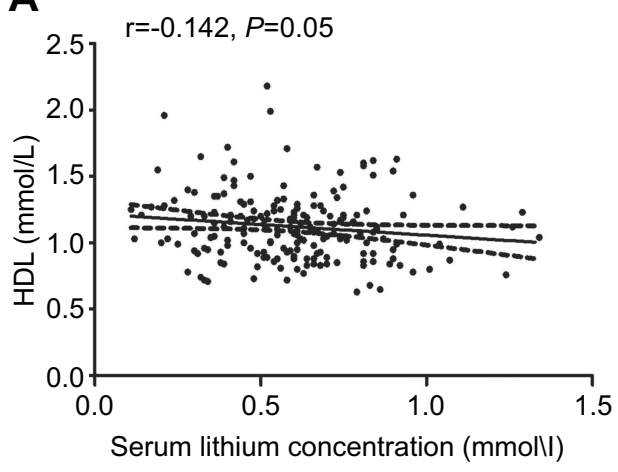

B

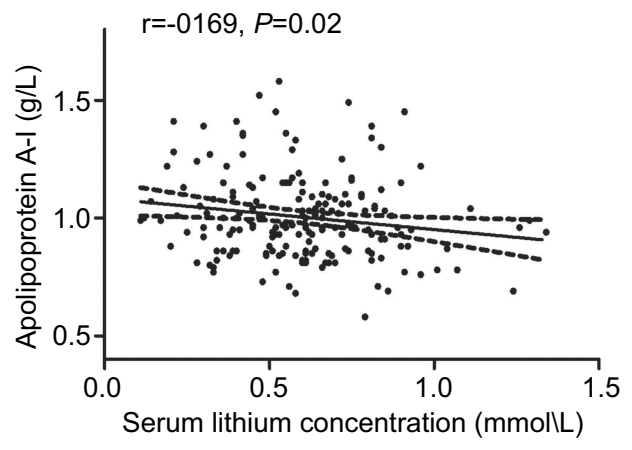

C

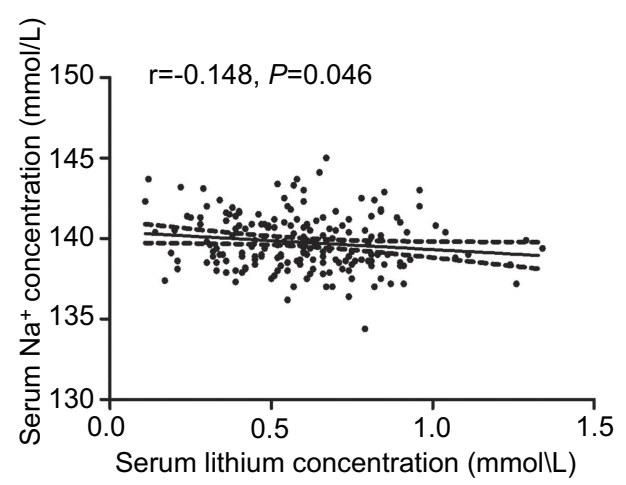

Figure 4 Negative correlations between the serum lithium concentration and $\mathrm{HDL}(\mathbf{A})$, apolipoprotein $\mathrm{Al}(\mathbf{B})$, and $\mathrm{Na}^{+}$concentrations $(\mathbf{C})$ in 86 patients with bipolar disorder.

Note: These data are normally distributed (Kolmogorov-Smirnov test). $P<0.05$ (two-tailed) was considered statistically significant.

Lithium preparations have been successfully used to treat $\mathrm{BD}$ and remain the best established long-term treatment for the disorder. ${ }^{19}$ Because lithium is an agent with a low therapeutic index and as such requires careful monitoring for adverse effects, especially in long-term treatment, identification of factors influencing blood lithium concentration, achievement of a safe and stable blood concentration, and a reduction in adverse reactions of lithium are of great clinical value.

Serum creatinine measurement is a fast, effective and reliable measurement method for accurate estimation of GFR and is therefore considered the gold standard for measuring changes in kidney function and identifying acute kidney injury (AKI). ${ }^{20}$ As renal insufficiency is clearly a very important potential clinical side effect of lithium, ${ }^{21}$ a statistically significant increase in blood creatinine was found to be associated with short-term ${ }^{22,23}$ and long-term ${ }^{24,25}$ lithium treatment. In a population pharmacokinetic analysis, lithium measurements were described using a two-compartment model, and the most significant covariate for lithium clearance was found to be creatinine clearance. ${ }^{9}$ More recently, long-term lithium treatment was reported to be associated with a decline in renal function as expressed by significant decreases in estimated GFR over time. ${ }^{25}$ Consistently, a positive relationship was observed between serum lithium concentrations and creatinine concentrations in the present study, indicating that renal insufficiency might increase serum lithium concentrations. Taken together, these studies suggest that lithium treatment requires continuous monitoring of renal function, particularly when antihypertensive drugs, such as diuretics and renin-aldosterone system inhibitors, are utilized. $^{19}$

Recent studies support the notion that mood-stabilizing drugs (valproate or lithium) play an important role in lipid homeostasis and can be used as a prospective research target for the mechanism of action of these drugs. ${ }^{12,26} \mathrm{~A}$ previous study demonstrated that lithium inhibited the serum enzyme levels of HDL significantly and dosedependently. ${ }^{13}$ Similarly, the results of our study indicated that serum lithium concentrations were negatively correlated with HDL concentrations. Apolipoprotein A1 is the major protein component of HDL particles in blood. ${ }^{27}$ It has been suggested that apolipoprotein A1 is a candidate marker for showing the response to lithium treatment at 
Table 2 Multiple linear regression analysis between the serum lithium concentrations (dependent variable) and the creatinine, HDL, apolipoprotein $\mathrm{AI}, \mathrm{Na}^{+}, \mathrm{Mg}^{2+}$ concentrations, and percentage of neutrophils (independent variables)

\begin{tabular}{|c|c|c|c|c|c|c|c|}
\hline \multirow[t]{2}{*}{ Variables } & \multirow[t]{2}{*}{ B } & \multirow[t]{2}{*}{$\mathbf{t}$} & \multirow[t]{2}{*}{$P$} & \multicolumn{2}{|l|}{$95 \% \mathrm{Cl}$} & \multicolumn{2}{|c|}{ Collinearity statistics } \\
\hline & & & & Lower bound & Upper bound & Tolerance & Variation inflation factor \\
\hline Constant & 3.199 & 2.371 & 0.019 & 0.536 & 5.862 & & \\
\hline creatinine & 0.002 & 1.175 & 0.242 & -0.001 & 0.004 & 0.231 & 4.327 \\
\hline HDL & -0.035 & -0.263 & 0.792 & -0.293 & 0.224 & 0.227 & 4.408 \\
\hline apolipoprotein AI & -0.166 & -0.867 & 0.387 & -0.544 & 0.212 & 0.894 & 1.118 \\
\hline $\mathrm{Na}^{+}$ & -0.022 & -2.317 & $0.022 *$ & -0.041 & -0.003 & 0.971 & 1.030 \\
\hline $\mathrm{Mg}^{2+}$ & 0.384 & 1.515 & 0.132 & -0.117 & 0.885 & 0.876 & 1.142 \\
\hline Percentage of neutrophils & 0.004 & 2.341 & $0.020^{*}$ & 0.001 & 0.008 & 0.962 & 1.039 \\
\hline
\end{tabular}

Note: These data are normally distributed (Kolmogorov-Smirnov test). $P<0.05$ (two-tailed) was considered statistically significant.

Abbreviation: HDL, High-density lipoprotein.

the serum protein level. ${ }^{10}$ Consistent with these findings, the results of the present study have indicated a negative relationship between serum lithium concentrations and apolipoprotein A1 concentrations. However, the specific mechanism of these correlations remains unclear and requires further research.

Numerous studies have shown that there is a close relationship between blood lithium and $\mathrm{Na}^{+}$, the mechanism of which might be due to the expression of $\mathrm{Na}^{+} / \mathrm{K}^{+}$ ATPase,${ }^{28}$ a solute pump that pumps $\mathrm{Na}^{+}$out of cells while pumping $\mathrm{K}^{+}$into cells, both against their concentration gradients. ${ }^{29}$ An in vitro study demonstrated the adaptation of live HEK293 cell metabolism to prolonged exposure to a therapeutic concentration of lithium manifested as the upregulation of $\mathrm{Na}^{+} / \mathrm{K}^{+}$-ATPase expression and extracellular $\mathrm{Na}^{+}, 30$ which might lead to increased excretion of extracellular $\mathrm{Na}^{+}$through the kidney and eventually lead to a decrease in blood $\mathrm{Na}^{+}$. Considering the fact that a negative relationship between serum lithium concentrations and $\mathrm{Na}^{+}$concentrations was observed by both Pearson correlation tests and multivariate linear regression analysis in the present study, it is rational to assume that $\mathrm{Na}^{+}$concentrations may be an indicator for serum lithium concentrations. Additionally, a positive relationship between serum lithium concentrations and $\mathrm{Mg}^{2+}$ was also found in the present study, the mechanism of which remains unclear and might be related to the fact that lithium could compete with $\mathrm{Mg}^{2+}$ and thereby inhibit vasopressin-sensitive adenylyl cyclase. ${ }^{31}$ Due to the fact that several factors associated with electrolytes were not controlled for in the present study, more studies are clearly required to validate the cause-and-effect relationship between serum lithium concentrations and electrolytes.
Accumulating evidence supports an association between lithium and the number of cells in the blood. Lithium can increase WBC and neutrophil counts in both acutely ${ }^{32}$ and long term. ${ }^{33}$ This lithium-induced increase in WBCs has been used to successfully treat neutropenia during carbamazepine therapy. ${ }^{34,35}$ The mechanism of lithium increasing neutrophil count and total WBC is not fully understood, and its effect is difficult to quantify. However, various suggestions, including demargination, stimulation of granulocyte-macrophage colony-stimulating factor, and stimulation of cytokines, have been proposed. ${ }^{36,37}$ The results of the present study first indicated that serum lithium concentrations were positively correlated with the percentage of neutrophils in 186 Chinese Han patients with $\mathrm{BD}$, further suggesting a close relationship between the concentration of blood lithium and the number of neutrophils and providing a theoretical basis for clinicians to treat neutropenia with lithium.

There are several limitations of this study that should be noted. First, the sample size is relatively small and all subjects were recruited from a single hospital. Second, the data regarding thyroid function of the patients at sample collection should be included because lithium has many effects on thyroid physiology. ${ }^{38}$ Third, the causal relationship between the factors and blood lithium concentrations cannot be determined by the current research results and need to be investigated in future studies. Fourth, although all of the patients were drug free for at least 2 weeks, we were unable to take into account the probable long-term effects of previous drugs on kidney function. Fifth, the data regarding urine osmolality of the patients at sample collection should be included, for the reason that urine osmolality is an important indicator of renal function. Sixth, the baseline levels of factors related to blood lithium concentrations before medication was not observed. 
At the end of this study, we reached the conclusion that the physiological factors, including creatinine, HDL, apolipoprotein $\mathrm{A} 1, \mathrm{Na}^{+}$, and $\mathrm{Mg}^{2+}$ concentrations and percentage of neutrophils, might be related to the serum lithium concentrations in Chinese Han patients with BD. Multicentric and longitudinal studies are clearly required to validate the relationship between serum lithium concentrations and physiological factors in patients with BD.

\section{Disclosure}

The authors report no conflicts of interest in this work.

\section{References}

1. Grande I, Berk M, Birmaher B, Vieta E. Bipolar disorder. Lancet. 2016;387(10027):1561-1572. doi:10.1016/S0140-6736(15)00241-X

2. Hou L, Heilbronner U, Degenhardt F, et al. Genetic variants associated with response to lithium treatment in bipolar disorder: a genome-wide association study. Lancet. 2016;387(10023):10851093. doi:10.1016/S0140-6736(16)00143-4

3. Pisanu C, Melis C, Squassina A. Lithium pharmacogenetics: where do we stand? Drug Develop Res. 2016;77(7):368-373. doi:10.1002/ ddr.21341

4. Yan Z, Yang X, Wang L, Zhao Y, Yu L. Social change and birth cohort increase in loneliness among Chinese older adults: a crosstemporal meta-analysis, 1995-2011. Int Psychogeriatr. 2014;26 (11):1773-1781. doi:10.1017/S1041610214000921

5. Zhang L, Cao X-L, Wang S-B, et al. The prevalence of bipolar disorder in China: a meta-analysis. J Affect Disord. 2017;207:413421. doi:10.1016/j.jad.2016.08.062

6. Methaneethorn J. Population pharmacokinetic analyses of lithium: a systematic review. Eur J Drug Metab Pharmacokinet. 2018;43 (1):25-34. doi:10.1007/s13318-017-0421-2

7. Eldesoky ES, Kumar V, Alorainy MS, Hamdi MM, Derendorf H. Estimation of lithium clearance from routine clinical data in Egyptian bipolar patients. A population pharmacokinetic approach. Int J Clin Pharm Th. 2008;46(12):617-626.

8. Finley PR. Drug interactions with lithium: an update. Clin Pharmacokinet. 2016;55(8):925-941.

9. Perez-Castello I, Mangas-Sanjuan V, Gonzalez-Garcia I, et al. Population pharmacokinetic model of lithium and drug compliance assessment. Eur Neuropsychopharmacol. 2016;26(12):18681876.

10. Rej S, Beaulieu S, Segal M, et al. Lithium dosing and serum concentrations across the age spectrum: from early adulthood to the tenth decade of life. Drugs Aging. 2014;31(12):911-916. doi:10.1007/ s40266-014-0221-1

11. Brown NC, Andreazza AC, Young LT. An updated meta-analysis of oxidative stress markers in bipolar disorder. Psychiat Res. 2014;218 (1-2):61-68. doi:10.1016/j.psychres.2014.04.005

12. Sussulini A, Dihazi H, Banzato CE, et al. Apolipoprotein A-I as a candidate serum marker for the response to lithium treatment in bipolar disorder. Proteomics. 2011;11(2):261-269. doi:10.1002/ pmic. 201000371

13. Ahmad M, Elnakady Y, Farooq M, Wadaan M. Lithium induced toxicity in rats: blood serum chemistry, antioxidative enzymes in red blood cells and histopathological studies. Biol Pharm Bull. 2011;34(2):272-277.

14. Shen HC, Li JY, Lo YK. Lithium intoxication-induced acute parkinsonism complicated with hyperparathyroidism and nephrogenic diabetes insipidus: report of a case. Acta Neurol Taiwan. 2007;16 (4):231-233.
15. Grunfeld JP, Rossier BC. Lithium nephrotoxicity revisited. Nat Rev Nephrol. 2009;5(5):270-276. doi:10.1038/nrneph.2009.43

16. Matsuura H, Kimoto S, Harada I, Naemura S, Yamamuro K, Kishimoto T. Lithium carbonate as a treatment for paliperidone extended-release-induced leukopenia and neutropenia in a patient with schizoaffective disorder; a case report. BMC Psychiatry. 2016;16:161. doi:10.1186/s12888-016-0874-x

17. Sporn A, Gogtay N, Ortiz-Aguayo R, et al. Clozapine-induced neutropenia in children: management with lithium carbonate. $J$ Child Adol Psychop. 2003;13(3):401-404. doi:10.1089/ 104454603322572697

18. Yu W, Sun X, Li Y, Li M, Wang K, Li H. Population pharmacokinetics of lithium carbonate in young male healthy Chinese volunteers. Pharmacopsychiatry. 2016;49(5):177-181. doi:10.1055/s-0042103329

19. Sani G, Perugi G, Tondo L. Treatment of bipolar disorder in a lifetime perspective: is lithium still the best choice? Clin Drug Invest. 2017;37(3):713-727. doi:10.1007/s40261-017-0531-2

20. Pottel H, Delanaye P, Schaeffner E, et al. Estimating glomerular filtration rate for the full age spectrum from serum creatinine and cystatin $\mathrm{C}$. Nephrol Dial Transplant. 2017;32(3):497-507. doi:10.1093/ndt/gfw425

21. Castro VM, Roberson AM, McCoy TH, et al. Stratifying risk for renal insufficiency among lithium-treated patients: an electronic health record study. Neuropsychopharmacology. 2016;41(4):11381143. doi:10.1038/npp.2015.254

22. Paul R, Minay J, Cardwell C, Fogarty D, Kelly C. Meta-analysis of the effects of lithium usage on serum creatinine levels. $J$ Psychopharmacol. 2010;24(10):1425-1431. doi:10.1177/0269881109104930

23. Amitai M, Zivony A, Kronenberg S, et al. Short-term effects of lithium on white blood cell counts and on levels of serum thyroidstimulating hormone and creatinine in adolescent inpatients: a retrospective naturalistic study. J Child Adol Psychop. 2014;24(9):494500. doi:10.1089/cap.2013.0046

24. Bozikas V, Xafenias T, Andreou C, et al. Chronic renal insufficiency after long term lithium treatment. Psychiatriki. 2007;18(2):168-172.

25. Tondo L, Abramowicz M, Alda M, et al. Long-term lithium treatment in bipolar disorder: effects on glomerular filtration rate and other metabolic parameters. Int $J$ Bipolar Disord. 2017;5(1):27. doi:10.1186/s40345-017-0096-2

26. Dean B, Digney A, Sundram S, Thomas E, Scarr E. Plasma apolipoprotein $\mathrm{E}$ is decreased in schizophrenia spectrum and bipolar disorder. Psychiat Res. 2008;158(1):75-78. doi:10.1016/j. psychres.2007.05.008

27. Viktorinova A, Jurkovicova I, Fabryova L, et al. Abnormalities in the relationship of paraoxonase 1 with $\mathrm{HDL}$ and apolipoprotein A1 and their possible connection to HDL dysfunctionality in type 2 diabetes. Diabetes Res Clin Pr. 2018;140:174-182. doi:10.1016/j.diabres.2018.03.055

28. Banerjee U, Dasgupta A, Rout JK, Singh OP. Effects of lithium therapy on $\mathrm{Na}+-\mathrm{K}+-$ ATPase activity and lipid peroxidation in bipolar disorder. Prog Neuropsychopharmacol Biol Psychiatry. 2012;37 (1):56-61. doi:10.1016/j.pnpbp.2011.12.006

29. Cui X, Xie Z. Protein interaction and Na/K-ATPase-mediated signal transduction. Molecules. 2017;22(6):pii: E990.

30. Vosahlikova M, Ujcikova H, Chernyavskiy O, et al. Effect of therapeutic concentration of lithium on live HEK293 cells; increase of $\mathrm{Na}$ $(+) / \mathrm{K}(+)$-ATPase, change of overall protein composition and alteration of surface layer of plasma membrane. Biochim Biophys Acta Gen Subj. 2017;1861(5 Pt A):1099-1112. doi:10.1016/j.bbagen.2017.02.011

31. Gong R, Wang P, Dworkin L. What we need to know about the effect of lithium on the kidney. Am J Physiol Renal Physiol. 2016;311(6): F1168-F1171. doi:10.1152/ajprenal.00145.2016

32. Lapierre G, Stewart RB. Lithium carbonate and leukocytosis. Am J Hosp Pharm. 1980;37(11):1525-1528.

33. Carmen J, Okafor K, Ike E. The effects of lithium therapy on leukocytes: a 1-year follow-up study. J Natl Med Assoc. 1993;85 (4):301-303. 
34. Dumas R, Bardin P, Vedie C. Long-term treatment of clozapine-induced leukopenia with lithium: fast-onset agranulocytosis following lithium discontinuation. Prim Care Companion CNS Disord. 2016;18(1). doi:10.4088/PCC.15101841

35. Suraweera C, Hanwella R, de Silva V. Use of lithium in clozapineinduced neutropenia: a case report. BMC Res Notes. 2014;7:635. doi:10.1186/1756-0500-7-635

36. Ghaznavi S, Nakic M, Rao P, et al. Rechallenging with clozapine following neutropenia: treatment options for refractory schizophrenia. Am J Psychiatry. 2008;165(7):813-818. doi:10.1176/appi. ajp.2008.07111823
37. Phiel CJ, Klein PS. Molecular targets of lithium action. Annu Rev Pharmacol Toxicol. 2001;41:789-813. doi:10.1146/annurev. pharmtox.41.1.789

38. Sethy RR, Sinha VK. Effect of lithium on thyroid function in adolescents with mood disorder. Asian J Psychiatr. 2016;24:41-45. doi:10.1016/j.ajp.2016.08.004

\section{Publish your work in this journal}

Neuropsychiatric Disease and Treatment is an international, peerreviewed journal of clinical therapeutics and pharmacology focusing on concise rapid reporting of clinical or pre-clinical studies on a range of neuropsychiatric and neurological disorders. This journal is indexed on PubMed Central, the 'PsycINFO' database and CAS, and is the official journal of The International Neuropsychiatric Association (INA). The manuscript management system is completely online and includes a very quick and fair peer-review system, which is all easy to use. Visit http://www.dovepress.com/testimonials.php to read real quotes from published authors. 